\title{
PENDEKATAN NATURAL LANGUAGE PROCESSING PADA APLIKASI CHATBOT SEBAGAI ALAT BANTU CUSTOMER SERVICE
}

\author{
Sri Mulyatun ${ }^{1)}$, Hastari Utama ${ }^{2)}$, Ali Mustopa ${ }^{3)}$ \\ 1) Sistem Informasi Universitas Amikom Yogyakarta \\ ${ }^{2)}$ Teknik Informatika Universitas Amikom Yogyakarta \\ ${ }^{3)}$ Sistem Informasi Universitas Amikom Yogyakarta \\ email : $\underline{\text { sri.m@amikom.ac.id }{ }^{1)} \text {,hastariutama@outlook.com }{ }^{2)}}$ ali.m@amikom.ac.id $^{3)}$
}

\begin{abstract}
Abstraksi
Informasi mengenai Akademik adalah bagian sangat penting dalam kehidupan sehari-hari, dimana informasi Akademik tersebut diperoleh salah satunya dengan kosultasi langsung dengan customer service. Berdasarkan wawancara yang dilakukan terhadap beberapa mahasiswa. mahasiswa memperoleh informasi Akademik dengan cara berkunjung ke kampus dan bertanya langsung terhadap customer service.Penyampaian informasi Akademik tersebut dirasa kurang karena keterbatasan oleh waktu jam buka kampus, sedangkan banyak mahasiswa sangat membutuhkan informasi Akademik dan konsultasi Akademik dengan cepet dan tidak mau terikat oleh waktu buka kampus, bahkan mahasiswa mengalami masalah Akademik disaat kampus sudah tutup, dan membutuhkan konsultasi customer service. Dengan permasalahan tersebut maka banyak mahasiswa yang salah terima dalam mencerna informasi dari akademik. Untuk menyampaikan informasi Akademik yang tidak terikat oleh waktu buka kampus, Universitas AMIKOM Yogyakarta memerlukan suatu alat media layanan informasi Akademik yang dapat merespon setiap pertanyaan mahasiswa tanpa ada keterbatasan waktu dan jumlah customer service. Pada penelitian ini solusi yang diusulkan untuk masalah tersebut salah satunya dengan cara membangun sebuah aplikasi chatbot informasi Akademik (customer service virtual) dengan pendekatan Natural Language Processing dengan menggunakan medote Fuzzy String Matching sebagai media penalarannya. Teknologi chatbot merupakan salah satu bentuk aplikasi Natural Language Processing, NLP itu sendiri merupakan salah satu bidang ilmu Kecerdasan Buatan ( Artificial Intelligence ) yang mempelajari komunikasi antara manusia dengan komputer melalui bahasa alami.
\end{abstract}

Kata Kunci :

Kecerdasan buatan, bahasa alami, chatbot, customer service virtual, NLP, Fuzzy String Matching

\begin{abstract}
Academic information is a very important part of everyday life, where Academic information is obtained, one of which is through direct consultation with customer service. Based on interviews conducted with several students. Students get Academic information by visiting campus and asking directly to customer service. Submission of Academic information is deemed insufficient due to limited campus opening hours, while many students really need Academic information and Academic consultation quickly and do not want to be bound by campus opening times, even students experience academic problems when the campus is closed, and require customer service consultation. With these problems, many students mistakenly accept information from academics. To convey academic information that is not bound by campus opening times, Universitas AMIKOM Yogyakarta needs an Academic information service media tool that can respond to student questions without limitation of time and number of customer service. In this study, the proposed solution for this problem is by building an Academic information chatbot application (virtual customer service) with the Natural Language Processing approach by using the Fuzzy String Matching method as the reasoning medium. Chatbot technology is a form of Natural Language Processing application, NLP itself is a field of Artificial Intelligence which studies communication between humans and computers through natural language.
\end{abstract}

Keywords :

Artificial intelligence; natural language; chatbot; virtual customer service; NLP; Fuzzy String Matching

\section{Pendahuluan}

Informasi mengenai seputar perkuliahan termasuk dari biaya SPP dan lain lain adalah bagian sangat penting dalam kehidupan kampus, dimana informasi tersebut diperoleh salah satunya dengan bertanya langsung dengan customer service, tanya jawab tersebut dilakukan dengan cara tatap muka langsung dengan bagian customer service. Berdasarkan wawancara yang dilakukan terhadap beberapa mahasiswa di lingkungan kampus Universitas 
AMIKOM Yogyakarta diperoleh informasi kampus secara global pada website namun informasi yang mendasar dan detil mahasiswa harus datang langsung ke kampus, namun tidak semua terakomodasi dengan baik karena keterbatasan jumlah tenaga kerja pada bagian customer service.

Solusi yang diusulkan untuk masalah tersebut salah satunya dengan cara membangun sebuah aplikasi chatbot dengan pendekatan Natural Language Processing [1]. Teknologi chatbot merupakan salah satu bentuk aplikasi Natural Language Processing, NLP itu sendiri merupakan salah satu bidang ilmu Kecerdasan Buatan (Artificial Intelligence) yang mempelajari komunikasi antara manusia dengan komputer melalui bahasa alami. Model komputasi seperti ini berguna untuk mmudahkan komunikasi antara manusia dengan komputer dalam hal pencarian informasi, sehingga dapat terjadi suatu interaksi antara keduanya dengan menggunakan bahasa alami.

Model komputasi seperti ini berguna untuk mmudahkan komunikasi antara manusia dengan komputer dalam hal pencarian informasi akademik, sehingga dapat terjadi suatu interaksi antara keduanya dengan menggunakan bahasa alami [2]. Aplikasi ini dibangun agar mahasiswa dapat mencari tahu tentang informasi akademik dengan cara tanya jawab kepada customer service Virtual. Mahasiswa tinggal memasukkan pertanyaan seputar akdemik atau masalah akademik berupa teks, kemudian customer virtual akan memberikan respon berupa jawaban atas pertanyaan yang diajukan.

Sehingga Memudahkan para mahasiswa dalam mendapatkan informasi baik akdemik mapun masalah masalah birokrasi akademik serta memberikan informasi dan solusi dengan apa yang ditanyakan, maka dalam penelitian ini penulis mengambil judul "

Rancang Bangun Aplikasi Chatbot Sebagai Alat Bantu Customer Service dengan Pendekatan Natural Language Processing ( Studi Kasus Universitas AMIKOM Yogyakarta )".

Kecerdasan buatan adalah proses analisis berbasis komputer yang cenderung menciptakan sistem komputasi yang kita akan cenderung untuk disebut cerdas. Sistem pakar adalah bagian paling penting dari kecerdasan buatan dari perspektif ekonomi [3]. Sistem pakar mencoba untuk meniru proses pemikiran manusia termasuk penalaran dan optimasi. "Pengetahuan" diwakili oleh satu set "jika-maka" aturan dalam bentuk basis pengetahuan. Hasil implementasi sistem kecerdasan buatan di penyulingan strategi pemasaran pelanggan berdasarkan lima faktor perilaku pelanggan: pendapatan, margin keuntungan, pangsa pasar, likuiditas, nilai jangka panjang, dan probabilitas retensi disajikan di koran. strategi pemasaran pelanggan tergantung pada kombinasi dari nilai lima atribut tersebut. sistem pakar membantu pemasar untuk "menelusuri" menjadi data dan mengidentifikasi pelanggan yang paling setia, memisahkan pelanggan ke dalam kelompok, dan merencanakan strategi pemasaran yang memadai. sistem pakar untuk menentukan strategi pelanggan pemasaran yang memadai dikembangkan menggunakan bahasa pemrograman Visual Prolog. Visual Prolog telah menunjukkan aplikasi yang memuaskan dan kekuasaan berkembang.

Penelitian ini diterapkan kecerdasan buatan untuk membantu perawat mengatasi masalah dan menerima instruksi melalui teknologi informasi [4]. Perawat membuat diagnosis menurut pengetahuan profesional, pengalaman klinis, dan bahkan naluri. Tanpa pengetahuan dan pemikiran yang komprehensif, akurasi diagnostik dapat dikompromikan dan keputusan mungkin tertunda. Kami menggunakan jaringan saraf back-propagasi dan alat-alat lain untuk pertambangan data dan analisis statistik. Kami lebih dibandingkan akurasi prediksi metode sebelumnya dengan sistem fuzzy inferensi berdasarkan adaptif-jaringan-dan jaringan syaraf back-propagation, mengidentifikasi perbedaan dalam pertanyaan dan tingkat kepuasan perawat sebelum dan setelah menggunakan sistem informasi keperawatan. Penelitian ini meneliti penggunaan kecerdasan buatan untuk menghasilkan diagnosa keperawatan. Persentase kesepakatan antara diagnosis disarankan oleh sistem informasi dan yang dilakukan oleh perawat adalah sebanyak 87 persen. Ketika mahasiswa dirawat di rumah sakit, kita dapat menghitung probabilitas dari berbagai diagnosa keperawatan berdasarkan karakteristik tertentu.

Dalam penelitian ini, penulis menggabungkan fitur ahlidipandu (teks) seleksi dengan klasifikasi satu kelas untuk pengolahan teks. Tujuan: Untuk membandingkan kinerja klasifikasi satu-kelas untuk klasifikasi biner tradisional; untuk mengevaluasi utilitas seleksi fitur berdasarkan ahli-teks yang dipilih menonjol (potongan); dan untuk menentukan kekokohan model ini dengan hal dengan teks sekitarnya tidak relevan [5].

Metode: Para penulis dilatih satu kelas dukungan mesin vektor

(1C-SVMs) dan dua kelas SVMs (2C-SVMs) untuk mengidentifikasi catatan membahas kanker payudara. Manual dijelaskan kunjungan Ringkasan catatan (88 positif dan 88 negatif untuk kanker payudara) digunakan untuk membandingkan kinerja model dilatih secara keseluruhan catatan dicap sebagai positif atau negatif untuk model dilatih pada bagian teks ahli-operator (potongan) yang relevan dengan status kanker payudara. kinerja model dievaluasi menggunakan 70:30 split untuk 20 iterasi dan pada dataset yang realistis dari 10000 catatan dengan prevalensi kanker payudara sebesar $1,4 \%$. Hasil: Ketika diuji pada dataset eksperimental yang seimbang, 1C-SVMs dilatih pada potongan memiliki hasil yang sebanding dengan 2C-SVMs dilatih secara keseluruhan catatan $(\mathrm{F}=0,92$ untuk kedua pendekatan). Ketika dievaluasi pada dataset 
seimbang realistis, 1C-SVMs memiliki kinerja yang jauh lebih unggul ( $\mathrm{F}=0,61$ vs $\mathrm{F}=0,17$ untuk model kinerja terbaik) disebabkan terutama untuk meningkatkan presisi ( $p=0,88$ vs $p=0,09$ untuk yang terbaik melakukan model).

Kesimpulan: 1C-SVMs dilatih pada bagian teks ahlioperator relevan tampil lebih baik dari pengklasifikasi 2C-SVMs dilatih di kedua potongan atau seluruh catatan bila diterapkan realistis data yang tidak seimbang dengan prevalensi rendah dari kelas positif.

Penyelidikan ini berkaitan dengan masalah identifikasi bahasa teks bising, yang bisa mewakili langkah utama dari banyak pengolahan bahasa alami atau pencarian informasi tugas [7]. Identifikasi bahasa adalah tugas otomatis mengidentifikasi bahasa dari teks yang diberikan. Meskipun ada ada beberapa metode dalam literatur, penampilan mereka tidak begitu meyakinkan dalam praktek. Dalam kontribusi ini, kami mengusulkan dua pendekatan statistik: pendekatan frekuensi tinggi dan pendekatan prototipe terdekat. Dalam yang pertama, 5 algoritma identifikasi bahasa diusulkan dan dilaksanakan, yaitu: identifikasi karakter identifikasi berdasarkan (CBA), kata berdasarkan identifikasi (WBA), karakter khusus berdasarkan (SCA), sekuensial algoritma hybrid (HA1) dan algoritma hybrid paralel ( HA2). Dalam satu detik, kita menggunakan 11 langkah kesamaan dikombinasikan dengan beberapa jenis karakter N-Grams. Untuk tugas evaluasi, metode yang diusulkan diuji pada dataset forum yang berisi 32 bahasa yang berbeda. Selanjutnya, perbandingan eksperimental dibuat antara pendekatan yang diusulkan dan beberapa identifikasi alat bahasa referensial seperti: LIGA, NTC, Google menerjemahkan dan Microsoft Word. Hasil penelitian menunjukkan bahwa pendekatan yang diusulkan menarik dan mengungguli metode dasar identifikasi bahasa pada teks forum.

Makalah ini membahas masalah mengubah spesifikasi bisnis ditulis dalam bahasa alami ke dalam model formal cocok untuk digunakan dalam pengembangan sistem informasi [6]. Ini mengusulkan metode untuk mengubah spesifikasi bahasa alami dikontrol berdasarkan Semantik Bisnis Kosakata dan standar Aturan Bisnis. Pendekatan ini adalah unik dalam menggabungkan teknik dari Model-Driven Mesin (MDE), Kognitif Linguistik, dan konfigurasi berbasis pengetahuan, yang memungkinkan pengolahan semantik diandalkan spesifikasi dan integrasi dengan alat MDE yang ada untuk meningkatkan produktivitas, kualitas, dan waktu-ke- pasar dalam pengembangan perangkat lunak. Metode pertama belajar kosakata spesifikasi dari definisi istilahseperti kemudian mem-parsing aturan spesifikasi dan output Model SBVR resmi yang dihasilkan. Kedua aspek metode diuji secara terpisah, dengan sistem dengan benar belajar $98 \%$ dari kosa kata dan benar menafsirkan $98 \%$ dari aturan contoh berdasarkan SBVR SE. Akhirnya, metoda yang diusulkan dibandingkan dengan negaraof-the-art pendekatan untuk menciptakan modelmodel resmi dari spesifikasi bahasa alami, dengan alasan bahwa itu memenuhi kriteria yang diperlukan untuk memenuhi tiga tujuan pengendalian (1) pergeseran dari spesifikasi untuk bisnis non-teknis ahli, (2) mengurangi upaya manual yang terlibat dalam spesifikasi meresmikan, dan (3) mendukung pakar bisnis dalam menciptakan set baik terbentuk dari kosakata bisnis dan aturan.

\section{Tinjauan Pustaka}

Kecerdasan buatan adalah proses analisis berbasis komputer yang cenderung menciptakan sistem komputasi yang kita akan cenderung untuk disebut cerdas. Sistem pakar adalah bagian paling penting dari kecerdasan buatan dari perspektif ekonomi [3]. Sistem pakar mencoba untuk meniru proses pemikiran manusia termasuk penalaran dan optimasi. "Pengetahuan" diwakili oleh satu set "jikamaka" aturan dalam bentuk basis pengetahuan. Hasil implementasi sistem kecerdasan buatan di penyulingan strategi pemasaran pelanggan berdasarkan lima faktor perilaku pelanggan: pendapatan, margin keuntungan, pangsa pasar, likuiditas, nilai jangka panjang, dan probabilitas retensi disajikan di koran. strategi pemasaran pelanggan tergantung pada kombinasi dari nilai lima atribut tersebut. sistem pakar membantu pemasar untuk "menelusuri" menjadi data dan mengidentifikasi pelanggan yang paling setia, memisahkan pelanggan ke dalam kelompok, dan merencanakan strategi pemasaran yang memadai. sistem pakar untuk menentukan strategi pelanggan pemasaran yang memadai dikembangkan menggunakan bahasa pemrograman Visual Prolog. Visual Prolog telah menunjukkan aplikasi yang memuaskan dan kekuasaan berkembang.

Penelitian ini diterapkan kecerdasan buatan untuk membantu perawat mengatasi masalah dan menerima instruksi melalui teknologi informasi [4]. Perawat membuat diagnosis menurut pengetahuan profesional, pengalaman klinis, dan bahkan naluri. Tanpa pengetahuan dan pemikiran yang komprehensif, akurasi diagnostik dapat dikompromikan dan keputusan mungkin tertunda. Kami menggunakan jaringan saraf back-propagasi dan alat-alat lain untuk pertambangan data dan analisis statistik. Kami lebih dibandingkan akurasi prediksi metode sebelumnya dengan sistem fuzzy inferensi berdasarkan adaptif-jaringan-dan jaringan syaraf back-propagation, mengidentifikasi perbedaan dalam pertanyaan dan tingkat kepuasan perawat sebelum dan setelah menggunakan sistem informasi keperawatan. Penelitian ini meneliti penggunaan kecerdasan buatan untuk menghasilkan diagnosa keperawatan. Persentase kesepakatan antara diagnosis disarankan oleh sistem informasi dan yang dilakukan oleh perawat adalah sebanyak 87 persen. 
Ketika mahasiswa dirawat di rumah sakit, kita dapat menghitung probabilitas dari berbagai diagnosa keperawatan berdasarkan karakteristik tertentu. Dalam penelitian ini, penulis menggabungkan fitur ahli-dipandu (teks) seleksi dengan klasifikasi satu kelas untuk pengolahan teks. Tujuan: Untuk membandingkan kinerja klasifikasi satu-kelas untuk klasifikasi biner tradisional; untuk mengevaluasi utilitas seleksi fitur berdasarkan ahli-teks yang dipilih menonjol (potongan); dan untuk menentukan kekokohan model ini dengan hal dengan teks sekitarnya tidak relevan [5]. Metode: Para penulis dilatih satu kelas dukungan mesin vektor (1C-SVMs) dan dua kelas SVMs (2C-SVMs) untuk mengidentifikasi catatan membahas kanker payudara. Manual dijelaskan kunjungan Ringkasan catatan (88 positif dan 88 negatif untuk kanker payudara) digunakan untuk membandingkan kinerja model dilatih secara keseluruhan catatan dicap sebagai positif atau negatif untuk model dilatih pada bagian teks ahli-operator (potongan) yang relevan dengan status kanker payudara. kinerja model dievaluasi menggunakan 70:30 split untuk 20 iterasi dan pada dataset yang realistis dari 10000 catatan dengan prevalensi kanker payudara sebesar 1,4\%. Hasil: Ketika diuji pada dataset eksperimental yang seimbang, 1C-SVMs dilatih pada potongan memiliki hasil yang sebanding dengan 2C-SVMs dilatih secara keseluruhan catatan $(\mathrm{F}=0,92$ untuk kedua pendekatan). Ketika dievaluasi pada dataset seimbang realistis, 1C-SVMs memiliki kinerja yang jauh lebih unggul ( $\mathrm{F}=0,61 \mathrm{vs} \mathrm{F}=0,17$ untuk model kinerja terbaik) disebabkan terutama untuk meningkatkan presisi ( $\mathrm{p}=0,88$ vs $\mathrm{p}=0,09$ untuk yang terbaik melakukan model). Kesimpulan: 1CSVMs dilatih pada bagian teks ahli-operator relevan tampil lebih baik dari pengklasifikasi 2C-SVMs dilatih di kedua potongan atau seluruh catatan bila diterapkan realistis data yang tidak seimbang dengan prevalensi rendah dari kelas positif.

Penyelidikan ini berkaitan dengan masalah identifikasi bahasa teks bising, yang bisa mewakili langkah utama dari banyak pengolahan bahasa alami atau pencarian informasi tugas [7]. Identifikasi bahasa adalah tugas otomatis mengidentifikasi bahasa dari teks yang diberikan. Meskipun ada ada beberapa metode dalam literatur, penampilan mereka tidak begitu meyakinkan dalam praktek. Dalam kontribusi ini, kami mengusulkan dua pendekatan statistik: pendekatan frekuensi tinggi dan pendekatan prototipe terdekat. Dalam yang pertama, 5 algoritma identifikasi bahasa diusulkan dan dilaksanakan, yaitu: identifikasi karakter identifikasi berdasarkan (CBA), kata berdasarkan identifikasi (WBA), karakter khusus berdasarkan (SCA), sekuensial algoritma hybrid (HA1) dan algoritma hybrid paralel ( HA2). Dalam satu detik, kita menggunakan 11 langkah kesamaan dikombinasikan dengan beberapa jenis karakter N-Grams. Untuk tugas evaluasi, metode yang diusulkan diuji pada dataset forum yang berisi 32 bahasa yang berbeda. Selanjutnya, perbandingan eksperimental dibuat antara pendekatan yang diusulkan dan beberapa identifikasi alat bahasa referensial seperti: LIGA, NTC, Google menerjemahkan dan Microsoft Word. Hasil penelitian menunjukkan bahwa pendekatan yang diusulkan menarik dan mengungguli metode dasar identifikasi bahasa pada teks forum.

Makalah ini membahas masalah mengubah spesifikasi bisnis ditulis dalam bahasa alami ke dalam model formal cocok untuk digunakan dalam pengembangan sistem informasi [6]. Ini mengusulkan metode untuk mengubah spesifikasi bahasa alami dikontrol berdasarkan Semantik Bisnis Kosakata dan standar Aturan Bisnis. Pendekatan ini adalah unik dalam menggabungkan teknik dari Model-Driven Mesin (MDE), Kognitif Linguistik, dan konfigurasi berbasis pengetahuan, yang memungkinkan pengolahan semantik diandalkan spesifikasi dan integrasi dengan alat MDE yang ada untuk meningkatkan produktivitas, kualitas, dan waktu-ke- pasar dalam pengembangan perangkat lunak. Metode pertama belajar kosakata spesifikasi dari definisi istilah-seperti kemudian mem-parsing aturan spesifikasi dan output Model SBVR resmi yang dihasilkan. Kedua aspek metode diuji secara terpisah, dengan sistem dengan benar belajar $98 \%$ dari kosa kata dan benar menafsirkan $98 \%$ dari aturan contoh berdasarkan SBVR SE. Akhirnya, metoda yang diusulkan dibandingkan dengan negaraof-the-art pendekatan untuk menciptakan modelmodel resmi dari spesifikasi bahasa alami, dengan alasan bahwa itu memenuhi kriteria yang diperlukan untuk memenuhi tiga tujuan pengendalian (1) pergeseran dari spesifikasi untuk bisnis non-teknis ahli, (2) mengurangi upaya manual yang terlibat dalam spesifikasi meresmikan, dan (3) mendukung pakar bisnis dalam menciptakan set baik terbentuk dari kosakata bisnis dan aturan.

\section{Metode Penelitian}

Metodologi penelitian yang dimaksud adalah segala hal yang berhubungan dengan metode-metode yang digunakan dalam membangun aplikasi ini dengan cara melakukan pendekatan terhadap metode-metode yang telah ada. Metode penelitian yang dipakai adalah metode penelitian deskriptif yaitu suatu metode yang bertujuan untuk mendapatkan gambaran yang jelas tentang hal-hal yang diperlukan. Metodologi penelitian ini memiliki dua tahapan, yaitu pengumpulan data dan pengembangan perangkat lunak.

\section{Metode Pengumpulan Data}

\section{A. Studi Pustaka}

Studi pustaka adalah segala usaha yang dilakukan oleh peneliti untuk menghimpun informasi yang relevan dengan topik atau masalah yang akan atau 
sedang diteliti. Studi pustaka dapat dilakukan dengan cara mempelajari, meneliti dan menelaah berbagai literatur-literatur yang bersumber dari bukubuku, teks, jurnal ilmiah, situr-situs di internet, dan bacaan-bacaan yang ada kaitannya dengan topik penelitian ini.

B. Studi Lapangan

Studi lapangan adalah salah satu proses kegiatan observasi pengungkapan fakta-fakta dalam proses memperoleh keterangan atau data. Studi ini dilakukan dengan cara mengunjungi tempat yang akan diteliti dan pengumpulan data dilakukan secara langsung. hal ini meliputi:

\section{Wawancara}

Wawancara yaitu metode pengumpulan data dengan cara mengadakan tanya jawab secara langsung dengan narasumber yang terkait dengan permasalahan yang diambil untuk memperoleh data dan informasi.

\section{Observasi}

Observasi yaitu metode pengumpulan data dengan cara melakukan pengamatan secara langsung terhadap objek permasalahan yang diambil.

\section{Kuesioner}

Kuesioner adalah suatu metode pengumpulan informasi yang memungkinkan analis mempelajari sikap-sikap, keyakinan, perilaku, dan karakteristik beberapa orang utama di dalam organisasi yang bisa terpengaruh oleh sistem yang diajukan atau oleh sistem yang sudah ada.

\section{Metode Pengembangan Perangkat Lunak}

Berdasarkan referensi yang didapatkan dari Summerville (2009), bahwa model pengembangan dalam membangun aplikasi chatBot customer services virtual ini menggunakan model waterfall. Alasan dipilihnya model waterfall karena tahapan prosesnya sangat tepat dan sesuai dalam pengembangan suatu perangkat lunak,yang meliputi beberapa proses diantaranya :

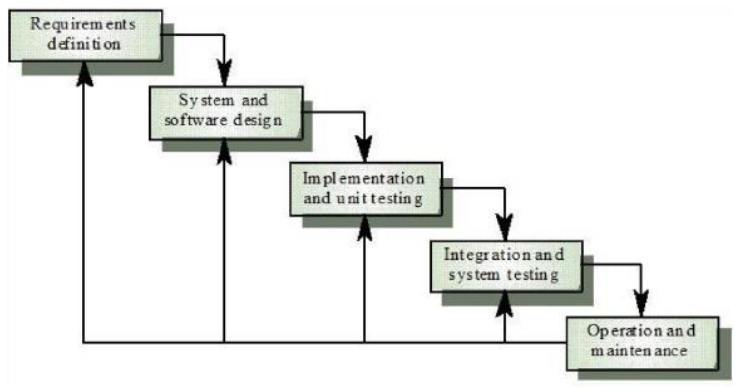

Gambar 1. Model Waterfall

\section{Hasil dan Pembahasan \\ A. Requirements analysis and definition}

Requirements analysis and definition adalah tahap Mengumpulkan semua kebutuhan data data konsultasi secara lengkap kemudian dianalisis dan didefinisikan kedalam bentuk yang mudah dimengerti oleh pengguna.

\section{B. System and software design}

System and software design adalah tahap menggambarkan dan perancangan system dam tampilan antar muka, baik itu huruf yang digunakan maupun background sebagai tampilan aplikasi chatbot customer services virtual.

\section{Implementation and unit testing}

Implementation and unit testing: adalah tahap penerjemahan data atau pemecahan masalah yang telah dirancang ke dalam bahasa pemrograman tertentu.

\section{Integration and system testing}

Integration and system testing adalah tahap Penyatuan unit-unit aplikasi chatBot customer services virtual kemudian diuji secara keseluruhan (system testing).

\section{E. Operation and maintenance}

Operation and maintenance adalah tahap mengoperasikan aplikasi customer services virtual dilingkungan kampus dan melakukan pemeliharaan, seperti penyesuaian atau perubahan karena adaptasi dengan situasi sebenarnya.

\section{Kesimpulan dan Saran}

Penelitian ini telah menempuh tahap selesai. Terdapat beberapa hal yang telah dilakukan serta dapat disimpulkan sebagai berikut:

1. Dalam penelitian ini telah dicapai analisis, perancangan, implementasi, pengujian dan publikasi.

2. Analisis dan perancangan dalam penelitian ini menggunakan pendekatan berorientasi objek. Diagram-diagram untuk perancangan dan pemodelan menggunakan UML.

3. Customer Service dapat dimudahkan dalam menanggapi pertanyaan pengunjung atau pelanggan yang bertanya tanpa harus menjawabnya secara manual.

4. Pendekatan Natural Language Processing pada aplikasi customer services, percakapan dan diskusi yang terjadi seprti layaknya dilakukan antara manusia dengan manusia. 
5. Dengan menggunakan metode Fuzzy String Matching sebagai penalaran kalimat, lebih memudahkan dalam pencarian keyword (pattern).

Pada penelitian ini ada beberapa saran untuk peningkatan penelitian selanjutnya. Saran-saran tersebut adalah sebagai berikut:

1. Kepintaran Customer Service virtual ditentukan oleh banyaknya brain file sehingga perbanyak data respons atau jawabannya.

2. Seorang admin harus sering meng-update data pattern/keyword agar pertanyaan-pertanyaan pengunjung memiliki jawaban yang sesuai dengan apa yang dimaksud pengunjung.

3. Agar pengunjung dapat mengira adalah manusia maka diperlukan beberapa tambahan fungsi seperti mengingat nama atau yang lainnya.

\section{Daftar Pustaka}

[1] Ian Sommerville , "Software Enguneering Ninth Edition”, Pearson, 2009

[2] Sri Kusumadewi. "Artificial Intelegence (Teknik dan Aplikasinya)", Graha Ilmu, Yogyakarta, 2003

[3] Brano Markić, Sanja Bijakšić, dan M. Šantić, "Artificial Intellegence in Determination of Marketing Customer Strategy", Journal of Informatologia. Mar 2015, Vol. 48 Issue 1/2, p39-47. 9p, 2015

[4] P.H. Liao, P.T. Hsu, W. Chu, dan, W.C. $\mathrm{Chu}$, Applying artificial intelligence technology to support decision-making in nursing: A case study in Taiwan", Health Informatics Journal. Jun 2015, Vol. 21 Issue 2, p137-148. 12p, 2015

[5] E. Joffe, E. Pettigrew, J. Herskovic, C. Bearden, dan E. Bernstam, "Expert guided natural language processing using oneclass classification", Journal of the American Medical Informatics Association, Sep 2015, Vol. 22 Issue 5, p962-966. 5p. 1 Diagram, 2 Charts, 2015

[6] M. Selway, G. Grossman, W. Mayer, dan M. Stumptner, "Formalising natural language specifications using a cognitive linguistic/configuration based approach", Journal of Information Systems. Dec 2015, Vol. 54, p191-208. 18p, 2015

[7] K.. Abainia, S. Ouamour, dan H. Sayoud, "Effective language identification of forum texts based on statistical approaches",
Journal of Information Processing \& Management. Jul 2016, Vol. 52 Issue 4, p491-512. 22p, 2016 